\title{
Expulsados de la globalización: políticas migratorias y deportados centroamericanos de José Luis Rocha

\author{
Miguel Huezo Mixco
}

Le agradezco infinitamente a la maestra Amparo Marroquín la invitación a participar como comentarista de este libro de José Luis Rocha. Me siento triplemente complacido. Primero, por el honor de sentarme al lado de Amparo, cuyo trabajo y sensibilidad admiro y aprecio. Amparo Marroquín es una de las intelectuales más brillantes de nuestro país y tiene mucho camino por delante. Por favor no olviden esto que les digo: este país tiene suerte de contar con una mujer como Amparo.

En segundo lugar, porque José Luis Rocha es hijo de un estimado poeta nicaragüense, a quien conocí hace algunos años cuando él formaba parte del directorio de $\mathrm{La}$ Prensa Literaria Centroamericana, un proyecto auspiciado por Pedro Joaquín Chamorro, ese

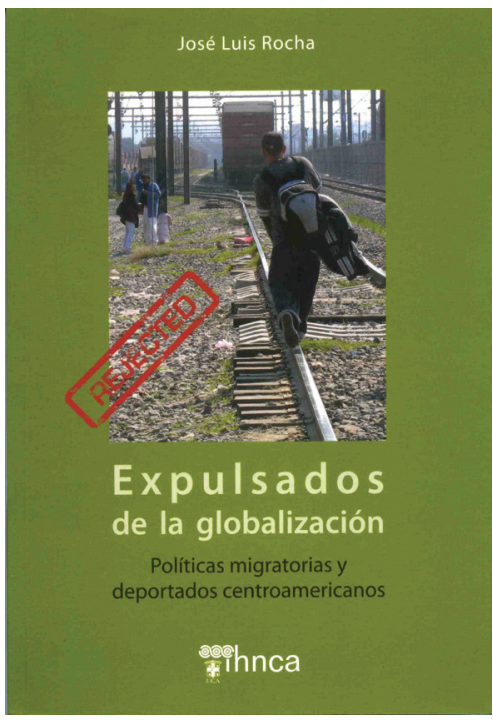
mártir de las libertades públicas. El padre de José Luis pertenece a la rica tradición literaria nicaragüense, una corriente con la que me siento muy identificado. Más que de Claudia Lars, Pedro Geoffroy Rivas o Hugo Lindo, me siento más cerca de Joaquín Pasos, Pablo Antonio Cuadra y Carlos Martínez Rivas. Siempre me he sentido como un salvadoreño "arrimado" a la tradición poética nicaragüense.

En tercer lugar, porque el tema del libro de José Luis -las migraciones internacionales, y en este caso las centroamericanas- constituye un tema apasionante. Se trata de una de las más grandes epopeyas de la historia del mundo. Las migraciones son una suerte de revolución pacífica protagonizada por los pobres, los desesperados, los "bárbaros", cuyas acciones está trasformando nuestra historia y nuestra cultura.

Se trata, además, de un libro que trae importante documentación y que ha sido escrito en un estilo bastante alejado del bla-bla académico, en donde abundan aquellos especialistas en decir mucho sin que se les entienda nada.

Esta revolución pacífica, como venía diciendo, está enfrentándose permanentemente con numerosas violencias; no sólo a la violencia de los poderes políticos y económicos, sino también a la violencia de la xenofobia y el crimen 
organizado. Por si fuera poco, a su paso por México, estas personas que corren peligros inmensos por encontrar un trabajo, también sufren escarnio y ultraje por parte de otros probablemente tan pobres y desesperados como ellos.

Conocí el libro de Rocha porque tuve la suerte de ser parte del jurado del Certamen convocado por la UCA y el Programa Desarrollo Humano y Migraciones, del PNUD, un programa que cuenta desde hace tres años con el generoso patrocinio de la Unión Europea. Como viene haciéndolo desde sus inicios, el Programa premió este libro que, como dice el autor, "trata de los centroamericanos que son castigados por querer trabajar donde no nacieron. (Y) describe las distintas facetas del castigo ejemplar al que son sometidos -la deportación- y los peligros asociados al incremento de los controles y barreras migratorias".

Como escribe Rocha: "La criminalización y penalización de las migraciones internacionales ha devenido en sentido común, plenamente legitimado por las leyes, la opinión pública y los aparatos coercitivos estatales. Los centroamericanos que quieren vivir el sueño americano son abruptamente despertados a una pesadilla de redadas, prisiones y deportaciones". Mucha de esta pesadilla proviene de lo que el autor, retomando un ensayo de Todorov, denomina "el miedo a los bárbaros", un miedo que se ha convertido en una verdadera pasión en los países industrializados, cuyas grandes ciudades son la meca de los migrantes.

Desde finales del siglo pasado las migraciones vienen constituyendo un tema central del debate académico y político a escala nacional, regional y global. Una buena parte de la agenda de discusión de las relaciones entre migraciones y el desarrollo ha estado dominada fundamentalmente por Estados Unidos y los países europeos receptores de migrantes.

Por su parte, los gobiernos de los países de origen y tránsito suelen adoptar un papel poco activo en este debate. La mayoría de las veces lo que escuchamos son discursos o reclamos en defensa de los migrantes, discursos que, como en un macabro Tarot, esconden la carta del estrepitoso fracaso de las políticas de desarrollo nacional. Un fracaso que en el caso de El Salvador obliga a que cada año 60 mil personas, la mayoría jóvenes, abandonen el país para encontrar trabajo y oportunidades de crecimiento personal y familiar. Esta cifra, equivale a 164 personas por día o, para ser más precisos, a un promedio entre $7 \mathrm{u}$ ocho personas por hora, que se van.

Este fracaso implica, como lo destaca el reciente Informe sobre Desarrollo Humano del PNUD, que de cada tres personas en edad de ingresar en el mercado laboral, dos han encontrado trabajo fuera del pais. Este fracaso, insisto, provoca grandes tragedias humanas, la mayoría desconocidas para nosotros, y que sólo saltan a la mirada del mundo cuando tienen la dimensión de lo ocurrido, por ejemplo, en Tamaulipas el año pasado.

Para sumar tragedias a tragedias, el asunto de los derechos humanos de los migrantes parece haberse convertido en un asunto poco interesante. Los derechos humanos siguen siendo el "patito feo" de los estudios y de los esfuerzos en políticas públicas, y probablemente es también el campo en donde se pueden exhibir menos victorias, porque aquí la cosa más bien ha ido para peor. El tema de los derechos humanos también se ha convertido en un asunto poco noticioso para los medios de comunicación de nuestros países, como lo muestra un reciente estudio coordinado 
por Amparo Marroquín, y que esperamos publicar próximamente como parte de nuestro Programa.

Como sabemos, la realidad trabaja con mucha rapidez, siempre va delante de nuestra capacidad de comprenderla. Por eso vivimos quejándonos de la realidad, de las leyes sobre migración, de la estupidez de los políticos, de los discursos de los gobernadores y de los gobernantes, de las groserías de las autoridades migratorias; de la estupidez, otra vez, de los xenófobos, de la criminalidad de los narcos, las pandillas y los policías federales.

La realidad nos ha convertido en expertos de la queja. Entre queja y queja a menudo olvidamos que también nosotros tenemos responsabilidades. Y una de esas responsabilidades consiste en aportar nuevos elementos teóricos y empíricos para entender la complejidad del fenómeno de las migraciones a fin de proponer alternativas de solución.

Y en este punto, quienes desde la academia o los organismos internacionales tenemos interés y emprendemos acciones sobre el tema de las migraciones, debemos comenzar por hacer una autocrítica profunda. Para empezar, necesitamos hacer una revisión de las bases conceptuales de los vínculos entre las migraciones y el desarrollo. Aquí hay tela para cortar.

Por otra parte, pese a la importancia que tienen, me parece inexplicable que todavía existan tan pocos estudios sobre las migraciones, que nos permitan entender el contexto, los procesos y los actores involucrados a lo largo del proceso migratorio. Sólo el estudio permanente del fenómeno migratorio nos ayudará a descubrir los nuevos problemas y dinámicas asociados a las causas, costos y contribuciones del fenómeno migratorio en su relación con el desarrollo.

Esta perspectiva requiere, desde luego, de indicadores y mejores bases de datos que revelen los costos y beneficios de las migraciones, y, una vez más, sus vínculos con el desarrollo.

Esto, de alguna manera, es un amistoso reclamo para que estudiosos como José Luis Rocha y Amparo Marroquín hagan más esfuerzos por ofrecer perspectivas novedosas y frescas sobre las migraciones.

En este caso, el libro de José Luis Rocha nos permite conocer mejor los mecanismos y las contradicciones del discurso anti-inmigrante, y nos propone mirar el empeño del cruce ilegal de fronteras como un gigantesco acto de desobediencia civil de dimensiones transnacionales. Una desobediencia que es expresión de una tremenda desesperación ante entornos sociales y económicos concebidos para excluir a los migrantes, a los otros, a los extraños.

Quiero finalizar utilizando una cita contenida en las páginas finales de este valiente libro: "Los migrantes, dice Rocha, ingresan con sobrado conocimiento de que su entrada no cuenta con la bendición legal de las autoridades ni con el beneplácito de una gran porción de la opinión pública. Pero saben que su acto tiene un carácter ambiguo. Por un lado es transgresor. Por otro tiene el respaldo de un principio elemental, fundacional: "Vamos buscando vida". 